\title{
Perceptions of people with leprosy about disease and treatment
}

\author{
Percepções de pessoas com hanseníase acerca da doença e tratamento
}

Vanessa Daniele Zambon Valério Pelizzari ${ }^{1}$, Guilherme Oliveira de Arruda ${ }^{1}$, Sônia Silva Marcon ${ }^{1}$, Carlos Alexandre Molena Fernandes ${ }^{1}$

Objective: to understand the perceptions of people with leprosy about disease and treatment. Methods: qualitative study conducted with nine adults in chemotherapy treatment. Data was collected through semistructured interviews and submitted to content analysis in thematic modality. Results: participants reported a concern, distrust, and resistance to accepting the diagnosis. When diagnosed, they felt shame and fear of suffering prejudice. Living with the disease caused important changes, such as the inability to get out, to exercise or perform leisure activities, but the improvement resulting from treatment reassured them, and the need to care for a dependent care motivated them to do it. Families expressed attention, and care was recognized as important, and the absence of these events meant abandonment and exclusion. Conclusion: people with leprosy have demanded not always identified by health professionals, but they had repercussions in the management of the treatment and welfare of these people.

Descriptors: Leprosy; Community Health Nursing; Therapeutics; Diagnosis; Family Relations.

Objetivo: compreender as percepções de pessoas com hanseníase acerca da doença e tratamento. Métodos: estudo qualitativo, realizado com nove adultos em tratamento poliquimioterápico. Dados coletados mediante entrevista semiestruturada e submetidos à análise de conteúdo, modalidade temática. Resultados: os participantes relataram preocupação, desconfiança e resistência em aceitar o diagnóstico. Diagnosticados, sentiram vergonha e medo de sofrerem preconceito. Conviver com a doença provocou mudanças importantes, como a impossibilidade de saírem, se exercitarem ou realizarem atividades de lazer, mas a melhora advinda do tratamento os tranquilizou, e a necessidade de cuidar de um familiar dependente de cuidados lhes motivou a realizá-lo. As famílias que manifestaram atenção e cuidados foram reconhecidas como importantes; e a ausência dessas manifestações significou abandono e exclusão. Conclusão: pessoas com hanseníase apresentam demandas nem sempre identificadas pelos profissionais de saúde, mas estas repercutem no manejo do tratamento e bem-estar destas.

Descritores: Hanseníase; Enfermagem em Saúde Comunitária; Terapêutica; Diagnóstico; Relações Familiares.

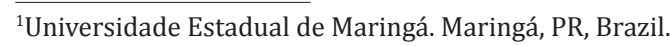




\section{Introduction}

Leprosy is a granulomatous and infectious disease, a chronic disease that manifests mainly by skin lesions with decreased thermal, painful and tactile sensitivity. It comes from an infection caused by Mycobacterium leprae (M. lepra), it has low pathogenicity and high infectivity characteristics and potentially incapacitating ${ }^{(1)}$.

The symptomatology load and therapy of the disease for the person with leprosy comes with terror by the social memory of leprosy and the age-old stigma attached to the disease, noting the isolation, mutilation, and exclusion suffered in the past $^{(2)}$. However, in recent times, with the health care decentralization in Brazil, and with the coordination of the care network to health by the Primary Health Care and the teams of the Family Health Strategy, a person with leprosy started to be treated at home, with his family, and accompanied by professionals working in his residence ${ }^{(3)}$.

Cross-sectional study carried out in Londrina, Brazil, showed that people with leprosy had used the primary health care services, but did not receive the diagnosis of leprosy in these services ${ }^{(4)}$. Although there were advances in protocols of care for people with leprosy, there is the absence of collective action and involvement of families of people with the disease and the community. Therefore, besides the difficulty of diagnosis and treatment in primary care services, they also highlight perspectives limited to individual care and that does not cause social mobilization for disease control ${ }^{(4)}$.

Also, a study conducted with 18 people with the treatment of leprosy found that they had a long therapeutic period to actualize the diagnosis, and the lack of training of health professionals and the stigma, prejudice, and silence about the disease favored selfmedication and the late diagnosis ${ }^{(5)}$. In this context, it appears that leprosy, especially in its most serious and disabling forms, is related to poor health in quality of life $\mathrm{f}^{(6)}$. Thus, educational activities can increase the population's knowledge, promoting prevention and early diagnosis ${ }^{(7)}$.

From the above, and the need to know the perceptions of people with leprosy on the diagnosis and treatment of the disease, there were gaps in scientific knowledge in public health and nursing ${ }^{(8)}$, that is, how is the experience of these patients before and after the diagnosis and during treatment. Thus, the question is: what are the perceptions of people with leprosy about experiences with the process of the diagnosis and treatment of the disease? Thus, the objective of this study was to understand the perceptions of people with leprosy about disease and treatment.

\section{Methods}

It is a qualitative study with nine adults with leprosy living in a municipality located in the northwest of Paraná State, Brazil. Currently, doctors of Basic Health Units applying for the examination for the diagnosis of leprosy in the city and in the case of a positive result, the patient is referred to a Health Unit located in the central area of the city, which will be accompanied by a medical specialist, for the treatment of leprosy in the city is still centered.

Data were collected between May and June 2014 through a semi-structured interview on their homes. Study participants were people with a diagnosis of leprosy, aged over 18 years old in multidrug and assisted by the public system of municipal health treatment. The identification of these people came from the Central Health Unit, and the researcher included a nursing assistant who works in the leprosy program, implemented in this unit, to conduct home visits, where people were informed and invited to participate in the study.

When there was an agreement to participate, day and time were scheduled for the interview, which was guided by a script containing questions related to socio-demographic characteristics of patients and their families and the disease and its treatment with 
a central question: how did you receive the diagnosis and how is for you having leprosy? Talk about it. There were also two support questions: what are the difficulties? How it was and has been the reaction and the performance of your family? The interviews lasted an average of 40 minutes. They were recorded on a digital device with prior consent of the participant and later transcribed, preferably on the same day they were made. The transcribed material was edited to eliminate errors and language defects. However, they kept the original meaning of the words.

For understanding the perceptions manifested by individuals with leprosy, the data were subjected to content analysis, thematic modality, imposing strict rules for the analysis, and, therefore, becoming part of the content analyzed, through a theoretical and practical exercise ${ }^{(9)}$. The organizational stages of analysis considered in this study were: pre-analysis, material exploration and processing of data.

In the pre-analysis, the initial organization of the material comprising the acquisition of messages and approach to transcription and superficial reading was held. Through detailed reading, the corpus was constituted (data analysis) suitable for exploration and interpretation. The exploitation of the material is characterized by coding, in which the units of analysis were cut and aggregated from common indicators that are keywords that represent the themes found. The processing of the data allowed the categorization of the issues and the generation of inferences and interpretations that, confronted with the literature ${ }^{(9)}$, provided an understanding of the reality of the subjects and their families.

The study participants were informed about the research objectives, methodology, type of desired participation, risks and benefits of participation, being able to maintain the anonymity of the information provided by them and the right to give up the participation in the study at any time. Participants were identified with the letter " $\mathrm{R}$ " of "respondent," followed by the number corresponding to the order of application of the interviews, the letters " $M$ " or " $F$ " to indicate male or female and the other indicative number for their age.

The study complied with the formal requirements contained in the national and international regulatory standards of research involving human beings.

\section{Results}

The nine people in the study were $42-77$ years old (mean 57 years old), six male, seven had no mate, four were active in providing services, four were retired, and one was a housewife and all they had less than eight years of study. The lowest per capita income was around $R \$ 125.00$, and the highest was $R \$$ 1,424.00.

Regarding the situation of the treatment, three were finalizing the treatment; that was using the $12^{\text {nd }}$ medicine chart; three had already done six or more months of treatment, and only two were at the beginning, that is, between two and four months. Only one patient was already more than a year in treatment, and had their medication temporarily suspended due to anemia, but later they had resumed chemotherapy treatment.

From rereading the speeches of the participants, three categories were found: Faced with the disease: the first symptoms to confirm the diagnosis; Motivations, benefits, and difficulties related to the treatment of leprosy; Family as a support or exclusion.

\section{Faced with the disease: the first symptoms to confirm the diagnosis}

In the first category, the subjects reported the first signs and symptoms presented of leprosy, and they led them to seek medical attention. Among them, the loss of skin sensitivity, the appearance of diffuse patches with the edema of members and nodes were highlighted. E6 and E8, for example, associated the loss of sensation and spots, respectively, to the usual events ("crazes") or procedures previously performed, which could involve delay in seeking 
the correct diagnosis. I was cooking, I craze to mix in the pan, burn me and not see. I went to the health center; I talked to the girls, and they said it was not right (E6, F, 61 years). I went to the doctor because it started to give me some spots on the skin, and I thought it could be the reaction to the surgery I had done (E8, M, 45 years). It was normal, I had been in the health center before, I did the tests and did not give anything, there was a day that my foot was swelling, and then began to pop my body, it left some lumps. Then I went to the dermatologist so that I learned (E9, M, 42 years). When she cut my arm, she said there are people who when will take this, is the biggest scandal. I was already used to feel pain because I have done 16 surgeries (E5, F, 58 years).

When they were looking for professional support, the subjects had difficulties in knowing the correct diagnosis because the professionals thought the symptoms in different ways, which led the service users to seek different professional or even undergo different treatments and which did not contribute to the cure of leprosy, to the detriment of conduct based on differential diagnosis to accelerate the implementation of the correct therapy. Back in the 70s, I started to feel a fire in the feet, warmth in the feet and I started doing tests, a doctor who was speaking uric acid, another said it was the column (E1, M, 75 years). I went to the doctor in the health center, and he said it was allergies, and gave me some medicine, I took and nothing to improve and increasingly appearing more pellets, so I said that's not allergy, another doctor said it's something in the blood, then I took medicine for blood and nothing (E7, F, 44 years). First I went to several doctors that informed me of Dr. X, and then I started to deal with it (E2, M, 63 years).

In the case of E5, the exaggerated hopes to carry out the tests for the diagnosis led her to think she was being discriminated against by suspected of having the disease. E8, worried about his stay at work, he was told by the doctor not to socialize diagnosis, implying to hide even the rest of the health team. "You will be the last." Then I thought, my God, I am being discriminated, but no problem (E5, F, 58 years). ...It was not for me to talk to others what it was; it was not for me to comment, who told me it was Dr.X. I asked him if I had to lean on the service because we had a few days I was hurt, my hands were numb. No one gave me guidance because no one knows, I never mentioned it to anyone, the health center of the staff here no one knows that I have never touched on the subject, and I try not to talk about it too (E8, M, 45 years).

The statements reveal the living with the stigma and prejudice that pervade the face of leprosy by the people who have the disease. It was observed that the interviewed subjects reported feeling ashamed to say to others who possessed the disease, by believing that people might fear the disease or to prevent manifestations of prejudice. In this sense, it is interesting to note that even the doctor who accompanied the leprosy patients guided them not socialize diagnosis. I am embarrassed, friends look and keep asking: What do you have? What did you do to your foot? I am ashamed to tell. I say it was an allergy of the skin. I did not go to the house of others; I stopped going to the house of others. They were afraid to go, then I will not, I am here at home (E4, M, 77 years). When someone asks what I do, I say I am doing a delicate treatment, but I do not speak that I have leprosy because I do not like to talk because it is not cool. However, among the people who have the diseases, we talk on the subject (E6, F, 61 years). The service staff asked what it was, and I said it was burning, because of my service, I move with the boiler. It must be the warmth of the boiler, but I do not speak, I will not go on forever because it cannot. If someone asks me, I say that is stain skin. So they did not notice the prejudices because I do not speak what I have (E8, M, 45 years). However, when Iget ajob I will leave the house, but I will not talk because people are afraid of the disease, they are afraid of people passing the disease (E9, M, 42 years).

In the perception of the interviewees, getting the diagnosed with leprosy was a cause for concern, distrust, and resistance to accepting the diagnosis. In part, they said it did not expect "that," if the diagnosis of leprosy came to their lives. I did the exam, but frankly I thought I had not, I was sure that I had not. However, then the doctor said, "You have it." Hence I was suspicious of what I had taken (E6, F, 61 years). I never expected that this would happen to me. When I took the exam, and he gave me the news, I did not expect, because any of the family had these things (E7, F, 44 years).

Thus, although there are difficulties linked to leprosy diagnosis and living with the disease, the participants of this study also showed motivations, benefits and difficulties related to treatment as the category presented below.

\section{Motivations, benefits and difficulties related to the treatment of leprosy}

The possibility to improve with treatment appears to have brought them calm. Almost a year ago I received the news, I was worried, but then I started having treatment, and I felt better (E2, M, 63 years).

Among the subjects of this study, it was an almost unanimous perception that the treatment causes regression 
of the condition of leprosy, which generates greater welfare for individuals who are treated. Iam doing the treatmentright tosee how it goes. The back was very bad, very itched that turned up wounds. Now some time now no longer itched. The arms have vastly improved; the spots are fading (E3, M, 51 years). It is getting better, I take just right, had much numbness in the fingers, and it is improving. I had much pain in the arms; it was all red, and now there is no more, it is gone the redness and the plates (E8, M, 45 years).

Other issues, in addition to the perception of improvement, led the subjects to initiate and continue the treatment, as the possibility to go alone to the Basic Health Unit and the need to care for a family that depended exclusively and continuously on their care. I think I am good because now I can go alone, because before my daughter had to bring me (E4, M, 77 years). At first, I did not want to treat since I am to leave it there. However, then I thought about the special child I have to depend on me for everything. Moreover, if I do the treatment, who will take care of him? Because I could be in a wheelchair, I would lose the movement of arms and legs. Then I thought of him and started to take every day (E7, F, 44 years).

For E5, knowing that one of his acquaintances have had leprosy and who won the disease, gave him more confidence in the treatment. Moreover, living with a family member who has had leprosy also allowed E9 feel ready to deal with the disease. One of them has had, and he is now healthy. Moreover, that gives me, even more, strength because I see his skin and is healthy, beautiful (E5, F, 58 years). As my father has it already, I knew what I had to do with this disease (E9, M, 42 years).

Among the motivations and benefits, E1 reported difficulty in obtaining the most important drug in treating the disease. The wait for the drug, a few months before the end of the long treatment, may be a reason for distress for people with leprosy. I took it for nine months, later the drug did not come, the Technical Nursing called there to see and said they had already finished treatment, she said she was not finished and missing at least three months to a year, and now I am waiting (E1, M, 75 years).

From the disclosure of diagnosis and the course of treatment, there were changes in the lives of the people interviewed: the inability to leave home, travel, work or to enjoy other forms of leisure. However, some participants in the study proved to be resistant to reducing their activities and considered unnecessary this reduction because they are in treatment. Among the difficulties posed by the disease, E6 said that did not stop going out. I did not stop going anywhere, I am evangelical, go to church, I am well received (E6, F, 66 years).

E1 soughttoleave home as needed. I walkjustbecausemy feet hurts too much, then I do not travel. However, ifyou need to go somewhere I go, I go to the market, and I buy, I will I get my retirement (E1, M, 75 years). In turn, E4 abandoned some activities by physical limitations and not by stigma. However, I would rather the ball in the Social Center and stopped going because they hurt my legs, I rode a bike and today I am taking Rivotril because I am a hard time sleeping at night; then that soothes the burning leg I sleep (E4, M, 77 years).

In the daily treatment of the disease, the family to the participants of this study in some way represented something important to them, whether for positive or negative issues, as pointed out in the following category.

\section{Family as support or exclusion}

The concern of the subject with leprosy goes beyond the personal scope and reaches his family, resulting in attention and care demonstrations. A longer wanted to take me home, and I said I would not leave my house. They were all worried. My son in law who lives in Maringá called me, and he creates a chicken, said it would take me a cock for me to make soup because he thought I was weak, and I said I was fine, and he even sent it. The girls thought I was not going to work (E6, F, 66 years). A son who lives in the Home Prand have a car, he who took me there to the Dr. My family helps in the treatment (E1, M, 75 years).

In this sense, the family depends on the effort to be with the person with leprosy and contribute to the monitoring and coping with the disease. My daughter thought I was not sick because she said that I ate well. Then she saw as I was, I was crying in pain and said it was serious and started running with me in the consultations. My sister was very worried and always links to know how I am, how is burning. At first, I lived alone; then my daughter came to live with me. She was watching me at first because I could not walk with pain (E4, M, 77 years).

The E4 daughter mobilized to live with his father, 
especially at the beginning of the disease, when he had difficultywalking. On the other hand, some reports deserved attention by the lack of support from family members to people with leprosy. The absence of family participation goes from denial to participate in the consultations to the complete exclusion of the subject with the disease. E5 reported the measures taken by the youngest son surprised her, especially because, until then, she took care of the grandson, who was away from her. We lived together, but my son changed everything, dealt with our house. In his house, I do not go. He asked them not to enter. Even the balcony wall full of holes he capped not anything to go from here to there. He had a baby that I cared, but now who are caring is the other grandmother. He asked not to enter his gate, not to move to 5 years old (E5, F, 58 years). No one attended, went alone to consultations, to Curitiba, God and me, all alone (E3, M, 51 years). A brother treated me differently and felt very offended. He said it was to separate plate, cup, forks, spoons because he took. Even when we went to his house, my son and my sister took the vaccine did not catch. I said I was not contagious so because if it were to take had already caught the son and my sister to have more contact with me and they did not get (E7, F, 44 years).

It is known that transmission occurs mainly by the upper airways of people with clinical forms multibacillary (lepromatous and borderline) untreated. So there is no need to separate the belongings of the individual not to be shared with others.

\section{Discussion}

This study had some limitations, such as the non-adoption of a theoretical reference to support the analysis and discussion of the emotional and social aspects that emerged from the interviews, which would lead to further deepening the analytical exercise. It also constitutes a limitation the fact that the data come from a single encounter, which may have compromised the details of the reports, either by limiting the memory or lack of ties to the researchers.

However, the results may favor the empowerment of health professionals about the emotional and social aspects involved in the process of diagnosis and treatment of leprosy. Moreover, it has implications for practice, as it was pointed out the need to implement actions to support the selfcare of people with leprosy and that they must involve families, in addition to the multidisciplinary team. In these actions, not only the clinical aspects of the disease should be considered but also the subjectivity that permeates the person's relationship with illness in the family, at work and leisure.

Although in the present study, the first signs and atypical symptoms have been found, even if supposedly understood as indicative of past events or usual events, participants have sought the public health service, there has been a problem: the length of the diagnosis of leprosy, which in most of Brazil, is still late, about a year and a half to two years after the onset of symptoms ${ }^{(10)}$. Moreover, the lack of information about signs and symptoms, the difficulty in finding services, care and/or trained professionals to detect the disease, can be factors that influence the late diagnosis.

Also, some patients still live with the stigma and prejudice of leprosy. As shown in the qualitative study in Araçuaí health micro-region, located in the middle region of the Jequitinhonha Valley, in the northeastern state of Minas Gerais, Brazil, with the primary health care staff, there is still ignorance of the population for signs and symptoms of the disease, and distance from health professionals in the attention to leprosy, which contributes to the maintenance of stigma ${ }^{(11)}$.

It was found that, beyond prejudice, some subjects were surprised by the diagnosis. In this view, the family is possibly a parameter to indicate the possibility of contagion and the occurrence of the disease or even as a concern with the impact of the diagnosis on the family. In this sense, it is considered that the diagnosis of leprosy is significantly implicated in fear of rejection ${ }^{(2)}$. 
A problem raised was the delay in delivery of the medication. Bureaucracy in providing medicine by the state to the municipality often becomes a stumbling block for the treatment of disease and can trigger to leave the treatment. Currently, the municipality requested the drug to the Regional Health for the monthly dispensation. However there is this dispensation, it is necessary to fill in various forms and, if any data is lost, the drug is dispensed.

For nursing professionals, the main challenges faced in the control and elimination of leprosy are to keep people with the disease being treated, as well as work overload, lack of interdisciplinary perspective and treatments outside the enrolled community. Thus, it is also important to consider the barriers experienced by health professionals. In short, both men and women in treatment for leprosy refer important repercussions for their life, not necessarily from the treatment, but coming from a set of changes necessary to cope with the disease. In this regard, a study conducted with 40 people with leprosy treated at a referral center for dermatology in Ceará, Brazil, showed repercussions, including those related to the domestic sphere, care of family and physical image (for women) and changes in routine and adapt to the new condition (for men) ${ }^{(12)}$.

The family was an important factor in the daily treatment of the disease for the participants of this study, and some active family participation was positive, while for others, the lack of a welcoming attitude was negative in fighting the disease. In addition to advances in treatment and increased chances of cure and recovery, the family's has also undergone changes, becoming an important ally in the healing of people with leprosy ${ }^{(13)}$.

When the diagnosis of leprosy is revealed to the family, there is an impact on family life. Its intensity is closely linked to prior knowledge about the disease ${ }^{(2)}$. Some emotional stigma reactions can manifest in leaving procedures, both as regards the sick person as those that make up their social relationships ${ }^{(13)}$. These conceptions of the disease, by family members, remain alive in the social imaginary, even at the possibility of effective and free treatment, since it can suppress the transmission of the disease and increase the chance of cure. However, the absence of references to the work of health professionals and the families, in the speeches of the participants in this study, clinical practice still geared solely to the individual patient, and yet, still significant difficulties in effective diagnosis and treatment.

Study among people with leprosy and their family members showed that all family members were willing to support the ones affected by the disease, revealing further inconsistencies and deficiencies in knowledge, attitude and practice among people with leprosy and their family members, as everyone had intermediate level of knowledge about the disease, but the attitude towards the disease and the practices were not fully adequate ${ }^{(14)}$.

A study among household contacts of people with leprosy reveals little knowledge about the disease, which shows the need for monitoring and educational activities in more effective health. Still, it is highlighted that household contacts or communicating, most of the families of people with leprosy, are at greater risk of acquiring the disease and have relevance in the epidemiological chain ${ }^{(15)}$. Furthermore, it is believed that family better informed and imbued with the need to support the treatment and care of the person with leprosy, can contribute to controlling the disease.

Thus, anchoring us in the present study findings, it is considered that the approach to the family of the person with leprosy should be part of the set of actions to be developed by health teams in primary health care. However, not restricted to the control measure of disease transmission, but also for the purpose of information and solve doubts and minimize stigma, as a strategy for a positive family involvement. 


\section{Conclusion}

This study enabled the knowledge of the perceptions of the experience of people with leprosy in treatment before and after diagnosis, and also about the present of stigma in their lives and their families. The diagnosis of leprosy consisted of concern, distrust, shame and resistance to accepting the diagnosis. In some cases, delayed diagnosis due, above all, the differences observed in multiple professional evaluations, represented stressor for these people. Moreover, the shame of their condition which reinforces the existence of a stigma was also reiterated by professional attitude.

About the treatment, it was found that certain factors such as the observation of improvement, the ability to perform everyday activities and the need to care for dependent care, emerged as motivators to continue to perform it properly. On the other hand, it was noted that where there was a shortage of medicines, the wait for this therapeutic resource represented source of anguish, as a rule, the product plays a central role in their lives during treatment. Looking to the illness phenomenon of the leprosy is enlarging, it was observed that the dynamics and Family posture constitute important aspects for people with the disease, either by the active participation of support or the unwelcoming attitude, marked by clearance or deletion. In any case, both are significant emerging reactions and feelings.

\section{Collaborations}

Pelizzari VDZV contributed in the design, data collection, analysis, data interpretation and writing of the article. Arruda GO contributed in the analysis, data interpretation and writing of the article. Marcon SS and Fernandes CAM contributed in the design and approval of the version to be published.

\section{References}

1. Ministério da Saúde (BR). Secretaria de Vigilância em Saúde. Guia de Vigilância em Saúde. Brasília: Ministério da Saúde; 2014.

2. Palmeira IP, Queiroz ABA, Ferreira MA. Marcas em si: vivenciando a dor do (auto) preconceito. Rev Bras Enferm. 2013; 66(6):893-900.

3. Lanza FM, Lana FCF. Decentralization of Leprosy Control Actions in the Micro-Region of Almenara, State of Minas Gerais. Rev Latino-am Enfermagem. 2011; 19(1):187-94.

4. Pieri FM, Touso MM, Rodrigues LBB, Yamamura M, Pinto IC, DessuntiEM, et al. Patients' perceptions on the performance of a local health system to eliminate leprosy, Parana State, Brazil. PLoS Negl Trop Dis. 2014; 8(1):1-10.

5. Martins PV, Iriart JAB. Itinerários terapêuticos de pacientes com diagnóstico de hanseníase em Salvador, Bahia. Rev Saúde Coletiva. 2014; 24(1):273-89.

6. Lustosa AA, Nogueira LT, Pedrosa JIS, Teles JBM, Campelo V. The impact of leprosy on health-related quality of life. Rev Soc Bras Med Trop. 2011; 44(5):6216.

7. Moreira AJ, Naves JM, Fernandes LRM, Castro SS, Walsh IAP. Ação educativa sobre hanseníase na população usuária das unidades básicas de saúde de Uberaba-MG. Saúde Debate. 2014; 38(101):234-43.

8. Viana LS, Aguiar, MIF, Aquino, DMC. Perfil socioepidemiológico e clínico de idosos afetados por hanseníase: contribuições para a enfermagem. J Res Fundam Care Online [Internet]. 2016 [citado 2016 abr 6]. 8(2):4435-46. Disponível em:http://www.seer.unirio.br/index.php/ cuidadofundamental/article/view/4593

9. Bardin L. Análise de conteúdo. São Paulo: Edições 70; 2011.

10. Nascimento GRC, Barrêto AJR, Brandão GCG, Tavares CM. Ações do enfermeiro no controle da hanseníase. Rev Eletr Enf [Internet]. 2011 [citado 2015 dez. 8]; 13(4):743-50. Disponível em: https://www.fen.ufg.br/fen_revista/v13/n4/ pdf/v13n4a20.pdf 
11. Lana FCF, Lanza FM, Carvalho APM, Tavares APN. 0 estigma em hanseníase e sua relação com as ações de controle. Rev Enferm UFSM. 2014; 4(3):55665.

12. Monte RS, Pereira MLD. Hansen's disease: social representations of affected people. Rev Rene. 2015; 16(6):863-71.

13. Bittencourt LP, Carmo AC, Leão AMM, Clos AC. Stigma: social perceptions reported by people affected by Hansen's disease. Rev Enferm UERJ. 2010; 18(2):185-90.
14. Stephen T, Selvaraj I, Parameswari PJ. Assessment of knowledge, attitude and practice about leprosy among patients and their families in a rural community in Tamil Nadu. Indian J Lepr. 2014; 86(1):7-14.

15. Sousa LM, Maranhão LC, Pires CAA, Rodrigues DM. Knowledge of household contacts of leprosy in the Primary Care in Ananindeua, Pará, Brazil. Rev Bras Med Fam Com. 2013; 8(26):20-3. 